\title{
Seed coating with arbuscular mycorrhizal fungi as an ecotechnological approach for sustainable agricultural production of common wheat (Triticum aestivum L.)
}

\author{
Rui S. Oliveira ${ }^{\mathrm{a}, \mathrm{b}, \mathrm{c}}$, Inês Rochaa, Ying Maa, Miroslav Vosátkad, and Helena Freitas ${ }^{\mathrm{a}}$
}

${ }^{a}$ Center for Functional Ecology, Department of Life Sciences, University of Coimbra, Coimbra, Portugal; ${ }^{b}$ Department of Environmental Health, Research Center on Health and Environment, School of Allied Health Sciences, Polytechnic Institute of Porto, Vila Nova de Gaia, Portugal; 'CBQF-Centro de Biotecnologia e Química Fina-Laboratório Associado, Escola Superior de Biotecnologia, Universidade Católica Portuguesa, Porto, Portugal; 'Institute of Botany, Academy of Sciences of the Czech Republic, Průhonice, Czech Republic

\begin{abstract}
The exploitation of arbuscular mycorrhizal (AM) fungi has become of great interest in agriculture due to their potential roles in reducing the need for agrochemicals, while improving plant growth and nutrition. Nevertheless, the application of AM fungi by dispersing inocula in granular form to open agricultural fields is not feasible because nontargeted spreading of inocula over large surface areas results in high cost per plant. Seed coating has the potential to significantly reduce the amount of inoculum needed, resulting in cost reduction and increased efficiency. The aim of this study was to assess whether seed coating with AM fungal inoculum is a feasible delivery system for production of common wheat (Triticum aestivum L.). Wheat seeds were coated with inoculum of Rhizophagus irregularis BEG140 and grown under different fertilization conditions: (1) none, (2) partial, or (3) complete. Data indicated that mycorrhizal inoculation via seed coating significantly increased the dry weight of shoot and seed spikes of wheat associated with reduced fertilization. Assessment of nutritional status of wheat showed that plants inoculated with $R$. irregularis via seed coating displayed enhanced stem concentrations of potassium (K), sulfur (S), and zinc ( $\mathrm{Zn})$. There were no significant differences in root colonization between plants conventionally inoculated with $R$. irregularis in soil and those inoculated via seed coating. Seed coating with AM fungi may be as effective as conventional soil inoculation and may contribute to reduce the utilization of chemical fertilizers. The application of AM via seed coating is proposed as an ecotechnological approach for sustainable agricultural wheat production.
\end{abstract}

The abuse of agrochemicals in order to maintain high yields in agriculture is a major global problem that compromises the environment and public health (Jackson et al., 2007; Meyer et al., 2010; Turra et al., 2010; Alavanja and Bonner, 2012; Burns et al., 2013; Freire et al., 2015). There is thus an urgent need to find sustainable alternatives to intensive agriculture. Plant growth-promoting microorganisms (PGPM) can serve as an environmentally friendly alternative and, consequently, a natural route to ease the adverse pressure on the environment derived from agricultural practices (Nadeem et al., 2014; Malusá et al., 2012). Arbuscular mycorrhizal (AM) fungi are a group of PGPM that establish a symbiotic association with plants (Oliveira et al., 2006). AM fungi were found to increase nutrient and water availability, protect plants from a variety of abiotic stresses and biotic stresses, and improve soil quality and structure (Oliveira et al., 2001, 2010, 2016; Miransari et al., 2009; Mäder et al., 2011).

With a total of 700 million tonnes of grain produced in 2011 (Mao et al., 2014), common wheat (Triticum aestivum L.) accounts for nearly $20 \%$ of the world's daily food supply (Berkman et al., 2012). Together with rice (Oryza sativa L.) and maize (Zea mays L.), wheat provides approximately two-thirds of all energy in human diets, emphasizing the economic importance and nutritional value of this crop (Cassman, 1999). 
In a recent study, Pellegrino et al. (2015) comprehensively reviewed the effects of AM fungi on wheat in field studies from 1975 to 2013. Mycorrhizal inoculation significantly improved wheat dry weight, phosphorus $(\mathrm{P})$, nitrogen $(\mathrm{N}$,$) and zinc (\mathrm{Zn})$ uptake and increased grain yield by $20 \%$. Pellegrino et al. (2015) concluded that AM fungal field inoculation may be an effective agronomic practice for wheat production. Further, other field and greenhouse studies using sterilized and nonsterilized soils revealed that AM fungal inoculation of wheat contributes to reducing the input of agrochemicals, especially the application of $\mathrm{P}$ fertilizer (Rubio et al., 2003; Mohammad et al., 2004; Babana and Antoun, 2006; Sharma et al., 2011; Aghili et al., 2014). Yet despite the proven benefits of AM fungi to wheat, there are no apparent feasible technologies available for their application in open agricultural fields. This may be due to the relatively high cost of inoculum and the need to attain a sufficient number of propagules per plant (Vosátka et al., 2012). Seed coating, a technique in which a certain active compound encompasses the seed, has the potential to allow the use of minor amounts of inoculum, resulting in cost reduction and efficiency increase (Ehsanfar and ModarresSanavy, 2005).

The aims of the present study were to (i) evaluate the effectiveness of seed coating as a delivery system for AM fungal inoculum and (ii) assess whether an AM fungus inoculated via seed coating reduces the need for fertilization in the production of common wheat.

\section{Materials and methods}

\section{Plant material and soil}

The seeds used in this study were from common wheat (Triticum aestivum L. cv. Roxo). The soil was collected from the uppermost $10-\mathrm{cm}$ layer of an organic farm in northern Portugal, sieved through a 4-mm mesh and autoclaved twice $\left(121^{\circ} \mathrm{C}\right.$ for $\left.25 \mathrm{~min}\right)$ on consecutive days. This was a sandy soil with $\mathrm{pH}(1: 2.5 \mathrm{w} / \mathrm{v}$ water $) 6.5$, electrical conductivity $0.1 \mathrm{dS} / \mathrm{m}, 1.2 \%$ organic matter, $3.8 \mathrm{~g} / \mathrm{kg}$ total $\mathrm{N}, 48.8 \mathrm{mg} / \mathrm{kg}$ extractable (EgnerRiehm) P, $4.3 \mathrm{~g} / \mathrm{kg}$ potassium (K), $1.6 \mathrm{~g} / \mathrm{kg}$ calcium (Ca), $66 \mathrm{mg} / \mathrm{kg}$ magnesium $(\mathrm{Mg})$, and $147 \mathrm{mg} / \mathrm{kg}$ sodium $(\mathrm{Na})$.

\section{Arbuscular mycorrhizal fungal inoculum and seed coating}

The AM fungal isolate Rhizophagus irregularis BEG140 was grown for 8 mo in a multispore pot culture containing a $1: 1(\mathrm{v} / \mathrm{v})$ mixture of zeolite and expanded clay with Trifolium pratense L. as host plant. Half of the inoculum was sieved through a 500- $\mu \mathrm{m}$ mesh and mixed with silicon dioxide $(1: 1 \mathrm{w} / \mathrm{w})$, which served as coating material (the inoculum-coating material mixture was provided by Symbiom Ltd., Czech Republic). Seeds of T. aestivum were misted with deionized water and coated by gradually adding the inoculum-coating material mixture according to the pan coating method (Scott et al., 1991). Coated seeds were then air dried at $25^{\circ} \mathrm{C}$ for $72 \mathrm{~h}$. Noninoculated control seeds were coated only with silicon dioxide. All seeds were used 1 mo after being coated.

\section{Greenhouse experiment}

Experimental units $\left(300-\mathrm{cm}^{3}\right.$ pots filled with soil) were arranged in a fully randomized manner using a $3 \times 3$ factorial design where the first factor was inoculation (noninoculated controls, $R$. irregularis conventionally inoculated in the soil [R.i.], and $R$. irregularis inoculated through seed coating [R.i. coat]) and the second factor was fertilization (no fertilization [F0], partial $80 \%$ strength Hoagland solution with $20 \%$ phosphorus [F1], and complete strength Hoagland solution [F2]). Each treatment combination was replicated six times. Pots of noninoculated control plants received one T. aestivum seed coated only with silicon dioxide. Pots from the R.i. treatments received $10 \mathrm{~g}$ nonsieved inoculum placed $2 \mathrm{~cm}$ below 1 uncoated seed, which corresponded to 4050 AM fungal propagules per plant, estimated by the most probable number method (Porter, 1979). Pots from the R.i. .coat $_{\text {treat- }}$ ments received 1 T. aestivum seed coated with $R$. irregularis, which corresponded to 42 AM fungal propagules per plant. In order to eliminate differences in microbial populations introduced with the AM fungal inoculum, $5 \mathrm{ml}$ of a suspension of AM fungal inoculum was added to each pot from the nonmycorrhizal treatments (Koide and $\mathrm{Li}$, 1989). The suspension was prepared as described 
by Oliveira et al. (2010). Fertilized plants received $25 \mathrm{ml}$ of the corresponding Hoagland solution (Taiz and Zeigher, 2002) per pot 3 times per week. Nonfertilized plants received $25 \mathrm{ml}$ deionized water. Plants were grown in a greenhouse under natural light with an average photoperiod of $12 \mathrm{~h}$. Temperature and relative humidity ranges were $14-42^{\circ} \mathrm{C}$ and $55-85 \%$, respectively. Pots of different treatments were periodically rotated to different bench positions to minimize differences due to their location in the greenhouse.

\section{Plant and fungal analyses}

After a growth period of $140 \mathrm{~d}$, plants were removed from the pots. The root system was separated from the shoot and washed to remove adhered soil. Shoots were dried at $70^{\circ} \mathrm{C}$ for $48 \mathrm{~h}$ and weighed. Seed spikes were separated from the stems and weighed. Stems were finely ground and digested according to the European Standard EN 13805 (European Committee for Standardization, 2014). Total P, K, Ca, Mg, sulfur (S), and zinc (Zn) were determined by inductively coupled plasma-optical emission spectrometry (ICP-OES; GBC Quantima, Australia). Operating conditions for ICP-OES determinations were as follows: $1000 \mathrm{~W}$ RF power-1000 W, $15 \mathrm{~L} / \mathrm{min}$ plasma gas flow rate, $1.2 \mathrm{~L} / \mathrm{min}$ auxiliary gas flow rate, 1 $\mathrm{L} / \mathrm{min}$ carrier gas flow rate, 50 scans/reading, 3 measurement replicates, and dual detector. Total $\mathrm{N}$ was determined with a segmented flow analyzer (Skalar, Inc., SanPlus, The Netherlands). Roots were cut into $1-\mathrm{cm}$ pieces and stained with trypan blue using a modified Phillips and Hayman (1970) protocol (Oliveira et al., 2005b). Percentage root length colonized (RLC) by AM fungi was assessed using the grid-line intersect method (Giovannetti and Mosse, 1980) under a stereomicroscope (Leica EZ4 HD, Germany). Stained root pieces were mounted on glass slides and examined with a compound microscope (Leica DM 5000-D, Germany) $(\times 100-400)$ to assess abundance of arbuscules and vesicles in the mycorrhizal root segments (Trouvelot et al., 1986). Arbuscule and vesicle abundances were determined using the software Mycocalc
(http://www.dijon.inra.fr/mychintec/Mycocalcprg/download.html) and expressed as percent colonized root length occupied by arbuscules and vesicles, respectively.

\section{Statistical analysis}

Normality and homogeneity of variances were confirmed and data were analyzed using two-way analysis of variance (ANOVA) for each dependent variable (plant and fungal parameters) versus independent variables (inoculation and fertilization). When a significant $F$ value was obtained $(p<$ $.05)$, treatment means were compared using Duncan's multiple range test. Fungal parameters data were analyzed without including the respective noninoculated control treatments. All statistical analyses were performed with the SPSS 20.0.0 software package (IBM SPSS Statistics, USA).

\section{Results and discussion}

\section{Effectiveness of seed coating as an inoculum delivery system}

Seeds from all treatments had a germination rate of $100 \%$, indicating that the coating process did not influence germination. There was no AM fungal colonization in the roots of non-inoculated plants (Figure 1C). All inoculated plants had root mycorrhizal colonization (Figures $1 \mathrm{~A}$ and $2 \mathrm{~A}$ ). There were no significant differences in percent RLC between plants conventionally inoculated with $R$. irregularis in the soil and those inoculated via seed coating (Figure $2 \mathrm{~A}$ and Table 1 ). Root colonization is a prerequisite for the functioning of AM symbiosis and for obtaining the plant benefits that are derived from this plant-fungus association (Smith and Read, 2008). Therefore, the primary objective of application of AM fungal inoculum to plants is to achieve root colonization. Data from the present study showed that application of inoculum through seed coating was as effective as soil inoculation in generating root colonization. However, inoculation via seed coating had the advantage of using a lower number of infective propagules per plant. Increasing the application of fertilizer resulted in a reduction of 


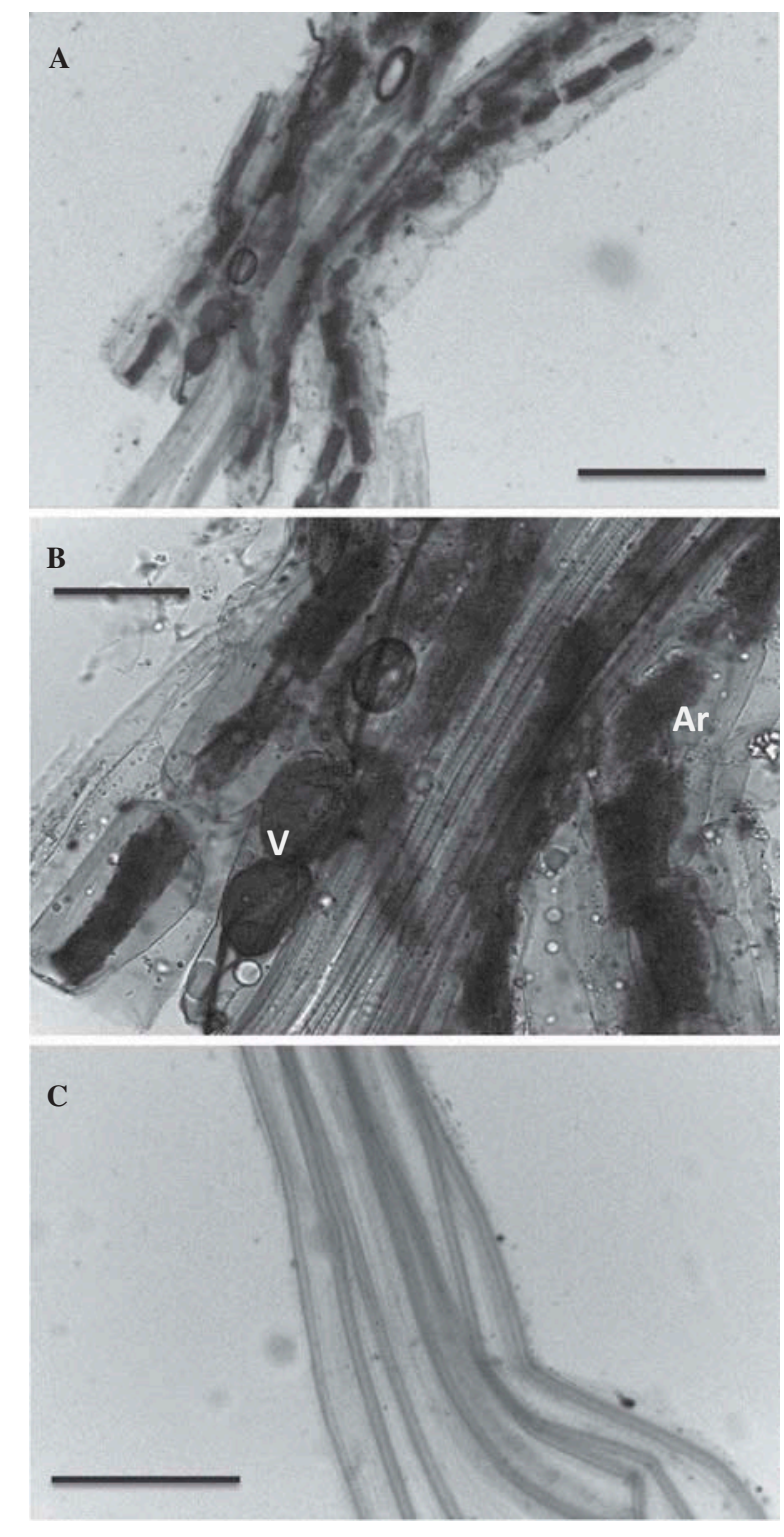

Figure 1. (A) Stained root of Triticum aestivum inoculated with Rhizophagus irregularis through seed coating, bar $150 \mu \mathrm{m}$. (B) Closeup of arbuscules (Ar) and vesicles (V), bar $94 \mu \mathrm{m}$. (C) Stained root of a noninoculated control plant, bar $225 \mu \mathrm{m}$.

percent RLC, irrespective of inoculation treatment (Figure 2A). Nutrient availability, particularly P, inhibits mycorrhizal colonization (Bhadalung et al., 2005; Smith et al., 2011). The lowest levels of percent RLC were obtained in plants that received the highest application of fertilizer and vice-versa.

Arbuscules and vesicles were found in the roots of all inoculated plants (Figure 1B). Complete fertilization significantly reduced arbuscule abundance in plants conventionally inoculated with $R$. irregularis in soil (Figure 2B). There were no significant differences in arbuscule abundance among all fertilization treatments of plants inoculated through seed coating. Arbuscules are highly specialized structures characteristic of AM fungi. Their role in the symbiosis is critical as these arbuscules are considered to be the main site for host-fungus nutrient exchange (Ryan et al., 2003; Smith and Read, 2008). Data demonstrated that arbuscule abundance of plants inoculated through seed coating is comparable to that of plants inoculated in the soil, rendering seed coating a viable technique for AM inoculation of wheat. Vesicle abundance in the mycorrhizal root segments was decreased in plants supplemented with full fertilization, irrespective of inoculation treatment (Figure 2C). There were no marked differences in arbuscule and vesicle abundances in the mycorrhizal root segments between plants inoculated with $R$. irregularis through seed coating and those with the inoculum applied in the soil (Table 1).

Thus, seed coating may serve as a valuable inoculum delivery system that enables successful mycorrhizal colonization with application of low numbers of infective propagules of AM fungi.

\section{Wheat growth and nutrition}

Application of AM fungi has the potential to diminish the utilization of chemical fertilizers in production of wheat (Graham and Abbott, 2000; Mohammad et al., 2004; Babana and Antoun, 2006). Considering such potential, this study aimed at assessing whether $R$. irregularis inoculated through coating of wheat seeds might contribute to reduction of the need for fertilization. Mycorrhizal inoculation and fertilization significantly influenced shoot dry weight of wheat (Table 2). Plants without fertilization (F0) displayed the lowest shoot dry weight values, irrespective of mycorrhizal inoculation. No significant differences in shoot dry weight of wheat inoculated with $R$. irregularis in soil were detected between plants that received partial fertilization (F1) and complete fertilization (F2). However, for wheat inoculated via seed coating, a significant elevation in shoot dry weight was observed in plants that received partial fertilization when compared with complete fertilization plants. The treatments that generated the greater dry 

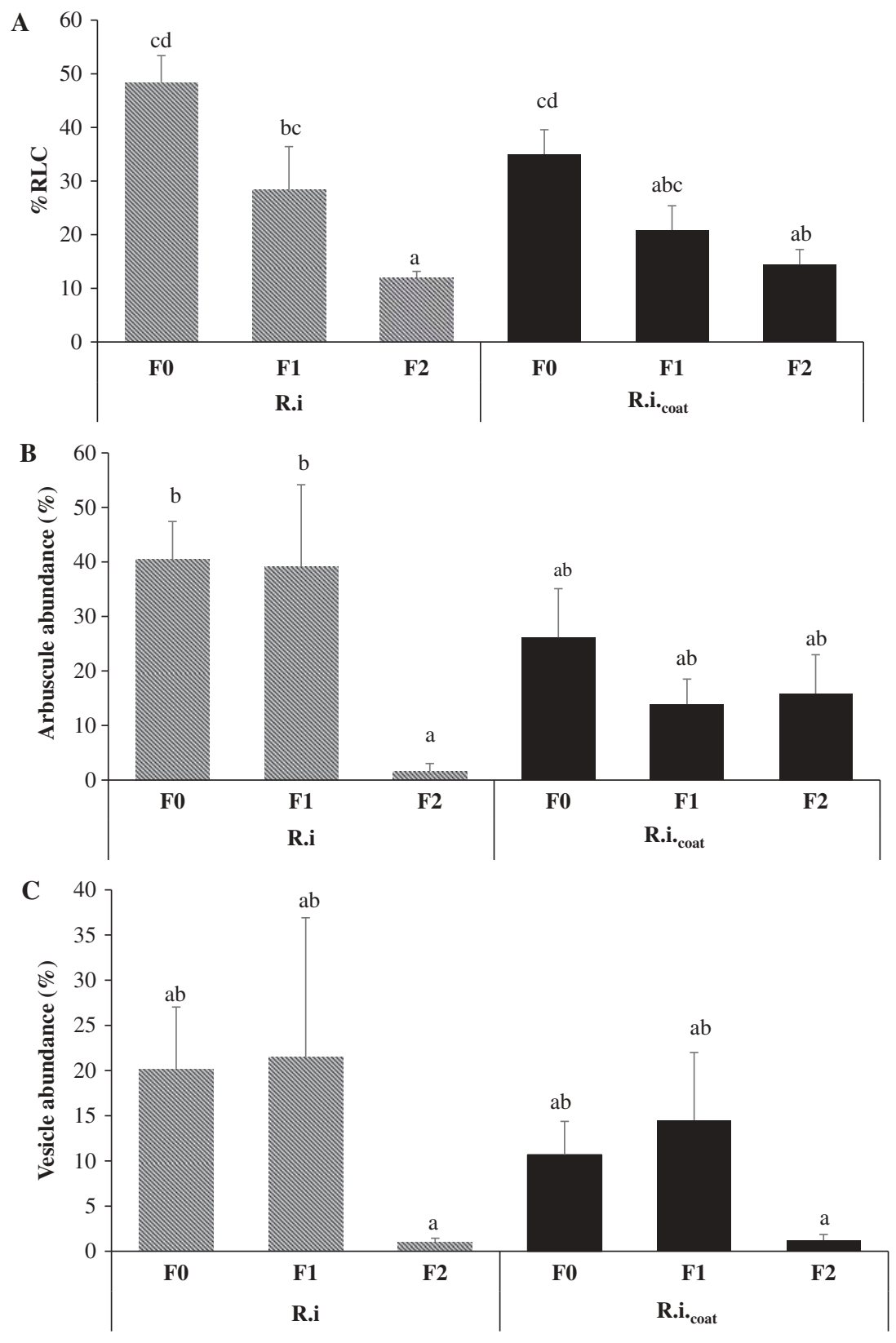

Figure 2. Percentage root length colonized (\%RLC) (A), arbuscule (B), and vesicle (C) abundances in the roots of Triticum aestivum conventionally inoculated with Rhizophagus irregularis in soil (R.i.) or through seed coating (R.i. .coat $_{\text {) }}$ under different fertilization regimes. Values are means $\pm 1 \mathrm{SE}$. Columns marked with the same letters are not significantly different according to Duncan's multiple range test at $p<.05$. F0, no fertilization; F1, 80\% strength Hoagland solution (with 20\% phosphorus); F2, full-strength Hoagland solution.

weight were: inoculation in soil + partial fertilization, inoculation in soil + complete fertilization, and inoculation via seed coating + partial fertilization. These findings indicated that by using seed coating as a method of inoculation it is possible not only to apply a considerably lower number of infective propagules, but also to reduce the application of fertilizer and still obtain improved wheat growth.
Both mycorrhizal inoculation and fertilization significantly influenced the weight of wheat seed spikes (Table 2). The weight of seed spikes of plants inoculated by seed coating and supplemented with partial fertilization increased by $383 \%$ in comparison with inoculated plants without fertilization, and by $460 \%$ in comparison with noninoculated control plants without fertilization. The weight of seed spikes is a yield indicator for 
Table 1. Mycorrhizal colonization parameters according to inoculation and fertilization.

\begin{tabular}{lccc}
\hline & AMF colonization (\%RLC) & Arbuscule abundance (\%) & Vesicle abundance (\%) \\
\hline Inoculation (I) & 2.3 & 1.4 & 1.2 \\
Fertilization (F) & $16.4^{*}$ & $4.6^{*}$ & $4.5^{*}$ \\
$\mathrm{I} \times \mathrm{F}$ & 1.2 & 2.6 & 0.4 \\
\hline
\end{tabular}

Note. Two-way ANOVA $F$ values followed by asterisk are significant at $p<.05$. AMF, arbuscular mycorrhizal fungal; RLC, root length colonized.

Table 2. Shoot and seed spike dry weight of Triticum aestivum under different inoculation treatments and fertilization regimes.

\begin{tabular}{|c|c|c|c|}
\hline Inoculation & Fertilization & Shoot dry weight $(\mathrm{g})$ & Seed spike dry weight $(\mathrm{g})$ \\
\hline \multirow[t]{3}{*}{ Control } & F0 & $0.14 \pm 0.01 \mathrm{a}$ & $0.05 \pm 0.01 \mathrm{a}$ \\
\hline & $\mathrm{F} 1$ & $0.51 \pm 0.05 b c$ & $0.15 \pm 0.03 b$ \\
\hline & $\mathrm{F} 2$ & $0.46 \pm 0.03 b$ & $0.13 \pm 0.02 b$ \\
\hline \multirow[t]{3}{*}{ R.i. } & F0 & $0.17 \pm 0.01 \mathrm{a}$ & $0.06 \pm 0.01 \mathrm{a}$ \\
\hline & $\mathrm{F} 1$ & $0.54 \pm 0.05 \mathrm{bcd}$ & $0.23 \pm 0.02 c$ \\
\hline & $\mathrm{F} 2$ & $0.58 \pm 0.05 \mathrm{~cd}$ & $0.23 \pm 0.04 c$ \\
\hline \multirow[t]{3}{*}{ R.i. } & F0 & $0.15 \pm 0.01 \mathrm{a}$ & $0.06 \pm 0.01 \mathrm{a}$ \\
\hline & $\mathrm{F} 1$ & $0.6 \pm 0.02 \mathrm{~d}$ & $0.23 \pm 0.02 c$ \\
\hline & $\mathrm{F} 2$ & $0.5 \pm 0.01 b c$ & $0.2 \pm 0.01 c$ \\
\hline \multicolumn{4}{|c|}{ Two-way ANOVA $F$ values and significances } \\
\hline Inoculation (I) & & $3.3^{*}$ & $11.1^{*}$ \\
\hline Fertilization (F) & & $177.2^{*}$ & $71^{*}$ \\
\hline $\mathrm{I} \times \mathrm{F}$ & & 1.7 & 1.8 \\
\hline
\end{tabular}

Note. Means ( $\pm 1 \mathrm{SE}$ ) followed by the same letters within each column are not significantly different according to Duncan's multiple range test. Asterisk indicates significant effect at $p<.05$. R.i., Rhizophagus irregularis conventionally inoculated in soil; R.i. coat, Rhizophagus irregularis inoculated through seed coating; F0, no fertilization; F1, $80 \%$ strength Hoagland solution (with 20\% phosphorus); F2, full-strength Hoagland solution.

wheat (Villegas et al., 2007). Grain formed in the spike is highly valued, as it is a major source of energy for the human diet (Karaoğlu et al., 2010). Therefore, increases in production of wheat seed spikes are of agronomic importance. Plants inoculated via seed coating and supplemented with partial fertilization demonstrated no marked differences in weight of seed spikes compared with plants that received complete fertilization. Results indicate that inoculation via seed coating + application of partial fertilization is the preferred treatment, as it enables a decrease in fertilizer application without compromising production of seed spikes in wheat.

Evaluation of nutritional status of wheat showed that mycorrhizal inoculation via seed coating significantly elevated $\mathrm{K}$ stem concentration of plants supplemented with partial or complete fertilizer dosage compared with controls (Table 3). Plants inoculated via seed coating and complete fertilization displayed enhanced concentration of $\mathrm{P}, \mathrm{S}$, and $\mathrm{Zn}$ compared with controls. The observed increases in stem concentrations of nutrients in inoculated plants were probably related to the capacity of $R$. irregularis to promote uptake of soil nutrients (Oliveira et al., 2005a, 2006;
Pellegrino et al., 2015). Improved mineral nutrition of wheat induced by AM fungal inoculation was previously reported (Aghili et al., 2014; Lehmann et al., 2014; Pellegrino et al., 2015). However, to our knowledge this is the first report of improved nutrition of plants inoculated with AM fungi via seed coating.

\section{Conclusions}

Inoculation of $R$. irregularis through seed coating resulted in consistent mycorrhizal colonization in wheat roots, demonstrating the potential of seed coating as an inoculum delivery system. Seed coating with mycorrhizal inoculum was as effective as soil inoculation in increasing dry weight of wheat shoot and seed spikes. Plants inoculated via seed coating displayed enhanced concentration of nutrients including $\mathrm{P}, \mathrm{K}, \mathrm{S}$, and $\mathrm{Zn}$. The observed growth improvement of inoculated plants was probably due to enhanced uptake of soil nutrients mediated by $R$. irregularis. To our knowledge this is the first report of seed coating with inoculum of AM fungi that successfully resulted in root colonization, plant growth, and nutritional improvement. Inoculation with mycorrhizal fungi via seed coating presents an 
Table 3. Stem nutrient concentrations of Triticum aestivum under different inoculation treatments and fertilization regimes.

\begin{tabular}{|c|c|c|c|c|c|c|c|c|}
\hline Inoculation & Fertilization & $N(g / k g)$ & $P(g / k g)$ & $\mathrm{K}(\mathrm{g} / \mathrm{kg})$ & $\mathrm{Ca}(\mathrm{g} / \mathrm{kg})$ & $M g(g / k g)$ & $\mathrm{S}(\mathrm{g} / \mathrm{kg})$ & $\mathrm{Zn}(\mathrm{mg} / \mathrm{kg})$ \\
\hline \multirow[t]{3}{*}{ Control } & F0 & $6.5 \pm 0.41 \mathrm{a}$ & $1.0 \pm 0.03 a$ & $34.8 \pm 0.19 a$ & $8.0 \pm 3.24$ & $0.6 \pm 0.01 a$ & $1.5 \pm 0.05 a$ & $42.2 \pm 1.2 \mathrm{a}$ \\
\hline & $\mathrm{F} 1$ & $17.0 \pm 1.04 \mathrm{c}$ & $2.4 \pm 0.19 \mathrm{bcd}$ & $37.2 \pm 3.55 a$ & $9.0 \pm 1.18$ & $1.4 \pm 0.31 b$ & $2.3 \pm 0.38 b$ & $50.0 \pm 3.46 \mathrm{ab}$ \\
\hline & F2 & $17.3 \pm 2.98 c$ & $2.5 \pm 0.47 \mathrm{~cd}$ & $38.6 \pm 5.10 \mathrm{a}$ & $8.2 \pm 2.84$ & $1.6 \pm 0.03 b$ & $1.9 \pm 0.11 \mathrm{ab}$ & $47.7 \pm 3.76 a b$ \\
\hline \multirow[t]{3}{*}{ R.i. } & F0 & $12.8 \pm 0.14 b c$ & $2.5 \pm 0.07 \mathrm{~cd}$ & $34.7 \pm 0.33 a$ & $8.4 \pm 2.60$ & $1.5 \pm 0.24 b$ & $2.0 \pm 0.08 a b$ & $50.9 \pm 2.57 \mathrm{ab}$ \\
\hline & F1 & $12.8 \pm 2.04 \mathrm{bc}$ & $1.2 \pm 0.37 \mathrm{ab}$ & $49.0 \pm 3.03 b c$ & $11.5 \pm 0.084$ & $1.3 \pm 0.06 \mathrm{ab}$ & $3.0 \pm 0.08 c$ & $44.1 \pm 2.05 \mathrm{a}$ \\
\hline & F2 & $17.9 \pm 0.90 c$ & $3.6 \pm 0.36 \mathrm{de}$ & $39.1 \pm 3.82 \mathrm{a}$ & $11.9 \pm 0.32$ & $1.3 \pm 0.39 a b$ & $3.1 \pm 0.11 c$ & $60.5 \pm 9.05 a b c$ \\
\hline \multirow[t]{3}{*}{ R.i. ${ }_{\text {coat }}$} & F0 & $7.9 \pm 0.17 \mathrm{ab}$ & $2.1 \pm 0.18 \mathrm{ab}$ & $40.2 \pm 3.03 a b$ & $9.6 \pm 2.61$ & $2.0 \pm 0.24 b$ & $2.1 \pm 0.15 a b$ & $67.6 \pm 9.79 b c$ \\
\hline & F1 & $17.7 \pm 2.49 c$ & $2.3 \pm 0.32 b c$ & $50.7 \pm 3.50 c$ & $12.6 \pm 2.05$ & $1.9 \pm 0.13 b$ & $2.5 \pm 0.44 \mathrm{bc}$ & $66.8 \pm 5.01 \mathrm{bc}$ \\
\hline & $\mathrm{F} 2$ & $17.5 \pm 2.52 c$ & $4.0 \pm 0.90 \mathrm{e}$ & $50.1 \pm 1.54 c$ & $11.1 \pm 1.97$ & $1.8 \pm 0.23 b$ & $3.0 \pm 0.20 c$ & $72.3 \pm 10.43 c$ \\
\hline \multicolumn{9}{|c|}{ Two-way ANOVA $F$ values and significances } \\
\hline \multicolumn{2}{|c|}{ Inoculation (I) } & 0.2 & 3.1 & $8.2^{*}$ & 1.3 & $7.7^{*}$ & $11.3^{*}$ & $10.5^{*}$ \\
\hline \multicolumn{2}{|c|}{ Fertilization (F) } & $19.7^{*}$ & $13.4^{*}$ & $6.6^{*}$ & 0.9 & 0.6 & $10.8^{*}$ & 1.1 \\
\hline \multicolumn{2}{|l|}{$\mathrm{I} \times \mathrm{F}$} & 2.8 & $3.8^{*}$ & 1.5 & 0.20 & 2.8 & 1.4 & 0.6 \\
\hline
\end{tabular}

Note. Means ( $\pm 1 \mathrm{SE}$ ) followed by the same letters within each column are not significantly different according to Duncan's multiple range test.

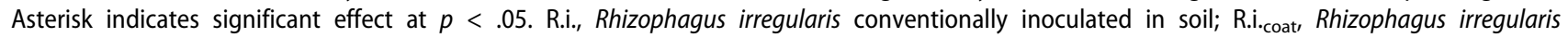
inoculated through seed coating; F0, no fertilization; F1, 80\% strength Hoagland solution (with 20\% phosphorus); F2, full-strength Hoagland solution.

important potential for large-scale agricultural wheat production, as it may generate economic and environmental benefits, derived from effective inoculation with a low number of infective propagules and reduction of chemical fertilizer application. Seed coating with AM fungi may therefore be regarded as an innovative ecotechnological approach for sustainable agriculture.

\section{Funding}

R. S. Oliveira and Y. Ma acknowledge the support of Fundação para a Ciência e a Tecnologia (FCT) through the research grants SFRH/BPD/85008/2012 and SFRH/BPD/ $76028 / 2011$ and Fundo Social Europeu. I. Rocha was supported by the FCT grant BI-EXPL/AGR-TEC/1204/2013. This work was financed by national funds through FCT under Project EXPL/AGR-TEC/1204/2013 and by Fundo Europeu de Desenvolvimento Regional (FEDER), Eixo I do Programa Operacional Fatores de Competitividade (POFC) of Quadro de Referência Estratégica Nacional (QREN) (COMPETE: FCOMP-01-0124-FEDER-041572). We thank Instituto Nacional de Investigação Agrária e Veterinária for providing the seeds.

\section{References}

Aghili, F., Jansa, J., Khoshgoftarmanesh, A. H., Afyuni, M., Schulin, R., Frossard, E., and Gamper, H. A. 2014. Wheat plants invest more in mycorrhizae and receive more benefits from them under adverse than favorable soil conditions. Appl. Soil Ecol. 84: 93-111.

Alavanja, M. C. R., and Bonner, M. R. 2012. Occupational pesticide exposures and cancer risk: A review. J. Toxicol. Environ. Health B 15: 238-263.

Babana, A. H., and Antoun, H. 2006. Effect of Tilemsi phosphate rock-solubilizing microorganisms on phosphorus uptake and yield of field-grown wheat (Triticum aestivum L.) in Mali. Plant Soil 287: 51-58.

Berkman, P. J., Lai, K., Lorenc, M. T., and Edwards, D. 2012. Next-generation sequencing applications for wheat crop improvement. Am. J. Bot. 99: 365-371.

Bhadalung, N. N., Suwanarit, A., Dell, B., Nopamornbodi, O., Thamchaipenet, A., and Rungchuang, J. 2005. Effects of long-term NP-fertilization on abundance and diversity of arbuscular mycorrhizal fungi under a maize cropping system. Plant Soil 270: 371-382.

Burns, C. J., McIntosh, L. J., Mink, P. J., Jurek, A. M., and Li, A. A. 2013. Pesticide exposure and neurodevelopmental outcomes: Review of the epidemiologic and animal studies. J. Toxicol. Environ. Health B 16: 127-283.

Cassman, K. G. 1999. Ecological intensification of cereal production systems: Yield potential, soil quality, and precision agriculture. Proc. Natl. Acad. Sci. USA 96: 5952-5959.

Ehsanfar, S., and Modarres-Sanavy, S. A. 2005. Crop protection by seed coating. Commun. Agric. Appl. Biol. Sci. 70: 225-229.

European Committee for Standardization. 2014. EN 13805. Foodstuffs-Determination of trace elements-Pressure digestion. Brussels, Belgium: European Committee for Standardization.

Freire, C., Koifman, R. J., and Koifman, S. 2015. Hematological and hepatic alterations in Brazilian population heavily exposed to organochlorine pesticides. J. Toxicol. Environ. Health A 78: 534-548. 
Giovannetti, M., and Mosse, B. 1980. An evaluation of techniques for measuring vesicular arbuscular mycorrhizal infection in roots. N. Phytol. 84: 489-500.

Graham, J. H., and Abbott, L. K. 2000. Wheat responses to aggressive and non-aggressive arbuscular mycorrhizal fungi. Plant Soil 220: 207-218.

Jackson, L. E., Pascual, U., and Hodgkin, T. 2007. Utilizing and conserving agrobiodiversity in agricultural landscapes. Agric. Ecosyst. Environ. 121: 196-210.

Karaoğlu M. M., Aydeniz M., Kotancilar M. H. G., and Gerçelaslan, K. E. 2010. A comparison of the functional characteristics of wheat stored as grain with wheat stored in spike form. J. Food Sci. Technol. 45: 38-47.

Koide, R. T., and Li, M. 1989. Appropriate controls for vesicular-arbuscular mycorrhiza research. N. Phytol. 111: 35-44.

Lehmann, A., Veresoglou, S. D., Leifheit, E. F., and Rillig, M. C. 2014. Arbuscular mycorrhizal influence on zinc nutrition in crop plants-A meta-analysis. Soil Biol. Biochem. 69: 123-131.

Mäder, P., Kaiser, F., Adholeya, A., Singh, R., Uppal, H. S., Sharma, A. K, Srivastava, R., Sahai, V., Aragno, M., Wiemken, A., Johri, B. N., and Fried, P. M. 2011. Inoculation of root microorganisms for sustainable wheat-rice and wheat-black gram rotations in India. Soil Biol. Biochem. 43: 609-619.

Malusá, E., Sas-Paszt, L., and Ciesielska, J. 2012. Technologies for beneficial microorganisms inocula used as biofertilizers. Sci. World J. 2012: article ID 491206.

Mao, L., Liu, Y., Shi, G., Jiang, S., Cheng, G., Li, X., An, L., and Feng, H. 2014. Wheat cultivars form distinctive communities of root-associated arbuscular mycorrhiza in a conventional agroecosystem. Plant Soil 374: 949-961.

Meyer, A., Koifman, S., Koifman, R. J., Moreira, J. C., de Rezende Chrisman, J., and Abreu-Villaca, Y. 2010. Mood disorders hospitalizations, suicide attempts, and suicide mortality among agricultural workers and residents in an area with intensive use of pesticides in Brazil. J. Toxicol. Environ. Health A 73: 866-877.

Miransari, M., Bahrami, H. A., Rejali, F., and Malakouti, M. J. 2009. Effects of arbuscular mycorrhiza, soil sterilization, and soil compaction on wheat (Triticum aestivum L.) nutrients uptake. Soil Till. Res. 104: 48-55.

Mohammad, A., Mitra, B., and Khan, A. G. 2004. Effects of sheared-root inoculum of Glomus intraradices on wheat grown at different phosphorus levels in the field. Agric. Ecosyst. Environ. 103: 245-249.

Nadeem, S. M., Ahmad, M., Zahir, Z. A., Javaid, A., and Ashraf, M. 2014. The role of mycorrhizae and plant growth promoting rhizobacteria (PGPR) in improving crop productivity under stressful environments. Biotechnol. Adv. 32: 429-448.

Oliveira, R. S., Boyer, L. R., Carvalho, M. F., Jeffries, P., Vosátka, M., Castro, P. M. L., and Dodd, J. C. 2010. Genetic, phenotypic and functional variation within a Glomus geosporum isolate cultivated with or without the stress of a highly alkaline anthropogenic sediment. Appl. Soil Ecol. 45: 39-48.
Oliveira, R. S., Castro, P. M. L., Dodd, J. C., and Vosátka, M. 2005a. Synergistic effect of Glomus intraradices and Frankia spp. on the growth and stress recovery of Alnus glutinosa in an alkaline anthropogenic sediment. Chemosphere 60: 1462-1470.

Oliveira, R. S., Castro, P. M. L., Dodd, J. C., and Vosátka, M. 2006. Different native arbuscular mycorrhizal fungi influence the coexistence of two plant species in a highly alkaline anthropogenic sediment. Plant Soil 287: 209-221.

Oliveira, R. S., Dodd, J. C., and Castro, P. M. L. 2001. The mycorrhizal status of Phragmites australis in several polluted soils and sediments of an industrialised region of northern Portugal. Mycorrhiza 10: 241-247.

Oliveira, R. S., Ma, Y., Rocha, I., Carvalho, M. F., Vosátka, M., and Freitas, H. 2016. Arbuscular mycorrhizal fungi are an alternative to the application of chemical fertilizer in the production of the medicinal and aromatic plant Coriandrum sativum L. J. Toxicol. Environ. Health A In press.

Oliveira R. S, Vosátka M., Dodd J. C., and Castro P. M. L. 2005b. Studies on the diversity of arbuscular mycorrhizal fungi and the efficacy of two native isolates in a highly alkaline anthropogenic sediment. Mycorrhiza 16: 23-31.

Pellegrino, E., Öpik, M., Bonari, E., and Ercoli, L. 2015. Responses of wheat to arbuscular mycorrhizal fungi: A meta-analysis of field studies from 1975 to 2013. Soil. Biol. Biochem. 84: 210-217.

Phillips, J. M., and Hayman, D. S. 1970. Improved procedures for clearing and staining parasitic and vesicular-arbuscular mycorrhizal fungi for rapid assessment of infection. Trans. Br. Mycol. Soc. 55: 158-161.

Porter, W. 1979. The "most probable number" method for enumerating infective propagules of vesicular arbuscular mycorrhizal fungi in soil. Aust. J. Soil Res. 17: 515-519.

Rubio, R., Borie, F., Schalchli, C., Castillo, C., and Azcón, R. 2003. Occurrence and effect of arbuscular mycorrhizal propagules in wheat as affected by the source and amount of phosphorus fertilizer and fungal inoculation. Appl. Soil Ecol. 23: 245-255.

Ryan, M. H., McCully, M. E., and Huang, C. X. 2003. Location and quantification of phosphorus and other elements in fully hydrated, soil-grown arbuscular mycorrhizas: A cryo-analytical scanning electron microscopy study. N. Phytol. 160: 429-441.

Scott, J. M., Hill, C. B., and Jessop, R. S. 1991. Growth chamber study of phosphorus applied as drilled granules or as seed coatings to wheat sown in soils differing in P-sorption capacity. Fertil. Res. 29: 281-287.

Sharma, M. P., Reddy, U. G., and Adholeya, A. 2011. Response of arbuscular mycorrhizal fungi on wheat (Triticum aestivum L.) grown conventionally and on beds in a sandy loam soil. Indian J. Microbiol. 51: 384-389.

Smith, S. E, Jakobsen, I., Grønlund, M., and Smith, F. A. 2011. Roles of arbuscular mycorrhizas in plant phosphorus nutrition: interactions between pathways of phosphorus uptake in arbuscular mycorrhizal roots have important implications for understanding and manipulating plant phosphorus acquisition. Plant Physiol. 156: 1050-1057. 
Smith, S. E., and Read, D. J. 2008. Mycorrhizal Symbiosis, 3rd ed. London, UK: Academic Press.

Taiz, L., and Zeiger, E. 2002. Plant physiology, 3rd ed. Sunderland, MA: Sinauer Associates Publishers.

Trouvelot, A., Kough, J. L., and Gianinazzi-Pearson, V. 1986. Mesure du taux de mycorhization VA d'un systeme radiculaire. Recherche de methodes d'estimation ayant une signification fonctionnelle. In Physiological and genetical aspects of mycorrhizae, ed. V. GianinazziPearson and S. Gianinazzi, 217-221. Paris, France: INRA Press

Turra, C., Fernandes E. A. D. N., Stefanuto, V. A., Bacchi, M. A., Sarriés, G. A., and Reyes, A. E. L. 2010. Arsenic and chromium in Brazilian agricultural supplies. J. Toxicol. Environ. Health A 73: 910-915.

Villegas, D., Moral, L. F. G., Rharrabti, Y., Martos, V., and Royo, C. 2007. Morphological traits above the flag leaf node as indicators of drought susceptibility index in durum wheat. $J$. Agron. Crop Sci. 193: 103-116.

Vosátka, M., Látr, A., Gianinazzi, S., and Albrechtová, J. 2012. Development of arbuscular mycorrhizal biotechnology and industry: Current achievements and bottlenecks. Symbiosis 58: $29-37$. 